\title{
Avaliação do controle de leptospirose por vacinação em bovinos de propriedade leiteira no estado do Piauí
}

\author{
Evaluation of leptospirosis control through vaccination in a cattle \\ dairy farm in the state of Piauí
}

\author{
Ana Lys Bezerra Barradas Mineiro ${ }^{1 *}$, Rômulo José Vieira ${ }^{1}$, Eduardo Esmeraldo Augusto Beserra², \\ Layana Mauriz Leal', Francisco Assis Leite Sousa', Ângela Piauilino Campos', \\ Élvio Carlos Moreira ${ }^{3}$, Francisco Assis Lima Costa'
}

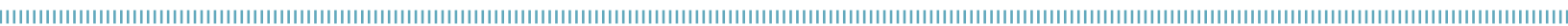

RESUMO: Neste estudo foram colhidos soros de 255 vacas e 2 touros no período de 2004 a 2009, em intervalos de seis meses, em uma fazenda de gado leiteiro no município de Buriti dos Lopes, Piauí. Pela técnica de soroaglutinação microscópica (SAM), os sorovares de leptospiras encontrados foram Hardjobovis, Hardjoprajitno (Norma), Hardjoprajitno (OMS). Para o controle da leptospirose, foi testada uma vacina contendo os mesmos sorovares encontrados infectando o rebanho. Os resultados mostraram que em bovinos leiteiros na bacia de Parnaíba, no Piauí, ocorre leptospirose, com predominância do sorovar Hardjobovis. A utilização de uma vacina contendo as sorovariedades mais prevalentes no rebanho, aplicada semestralmente ao longo de cinco anos, foi importante para a reduçáo dos títulos de anticorpos, além de reduzir os problemas reprodutivos no rebanho.

PALAVRAS-CHAVE: bovino de leite; imunoterapia; sorovares de leptospiras; vacina; problemas reprodutivos.

\begin{abstract}
For this study, we collected sera from 255 cows and 2 bulls in the period from 2004 to 2009, with six-month intervals, a dairy cattle farm in the municipality of Buriti dos Lopes, in the state of Piauí. By the microscopic agglutination test (MAT), we found the following serovars of leptospira: Hardjobovis, Hardjoprajitno (Norma), Hardjoprajitno (WHO). For the control of leptospirosis, a vaccine containing the same serovars that were found infecting the herd was tested. The results showed that in dairy cattle in the basin of Parnaiba, state of Piauí, leptospirosis occurs with a predominance of serovar Hardjobovis. The use of a vaccine containing the most prevalent serovars in the herd applied every six months during the course of five years was important to reduce antibody titers and reproductive problems in cattle.
\end{abstract}

KEYWORDS: dairy cattle; immunotherapy; serovars of leptospira; vaccine; reproductive problems.

'Departamento de Clínica e Cirurgia Veterinária; Universidade Federal do Piauí (UFPI) - Teresina (PI), Brasil.

${ }^{2}$ Instituto de Assistência Técnica e Extensão Rural do Piauí (PI) - Teresina (PI), Brasil.

${ }^{3}$ Departamento de Medicina Preventiva; Universidade Federal de Minas Gerais (UFMG) - Belo Horizonte (MG), Brasil.

*Autor correspondente: lysbarradas@yahoo.com.br

Recebido em: 02/11/2012. Aceito em: 01/03/2014 


\section{INTRODUÇÃO}

Os aspectos da epidemiologia da leptospirose em bovinos no Brasil merecem mais atenção por ser uma doença crônica, caracterizada principalmente por problemas reprodutivos (FAINE et al., 1999). A sorovariedade Hardjo aparece com elevada frequência (CASTro et al., 2008; Mineiro et al., 2010; Oliveira et al., 2010; MARTins et al., 2012; SiLVA et al., 2012), sendo que os genótipos Hardjobovis e Hardjoprajitno causam problemas reprodutivos em bovinos em todo o mundo (ELLis, 1994; Grooms, 2006; Oliveira et al., 2010).

A infecçãoo por Hardjobovis apresenta distribuição mundial, sendo caracterizada pela forma subclínica com sintomas de abortamento, enquanto que Hardjoprajitno, isolada em poucos países, é mais patogênica, levando à queda da produção do leite e a problemas reprodutivos (Ellis, 1994; Givens; Marley, 2008).

O genótipo Hardjoprajitno pertence à espécie Leptospira interrogans, enquanto Hardjobovis pertence à espécie Leptospira borgpetersenii (Perolat et al., 1994; Morey et al., 2006), por isso, nas vacinas, eles náo induzem imunidade cruzada (RAmadas et al., 1990). Desse modo, a elaboração de vacinas deve ser feita com o menor número possível de sorovariedades, com ênfase para aquelas presentes na regiáo (Bolin; Alt, 2001; Araujo et al., 2005). Nas vacinas antileptospira comercializadas no Brasil, são incluídos vários sorovares com baixa importância epidemiológica para a espécie bovina, o que pode levar a falhas na vacinaçáo, além da elevação desnecessária dos custos e interferência no diagnóstico (Rodrigues et al., 2011). Sabe-se que as vacinas comerciais são apenas parcialmente efetivas devido à natureza restrita dos sorovares presentes na sua formulaçáo, e à potencial presença de sorovares locais diferentes daqueles contidos na vacina (ADLER; Moctezuma, 2010).

A identificação das leptospiras que infectam um rebanho torna possível desenvolver uma vacina específica (FAINE et al., 1999; Chiareli et al., 2012). Por sua vez, essas vacinas podem gerar reaçóes cruzadas nos animais, induzindo resposta imunológica que não apresenta títulos uniformes para as diferentes sorovariedades (Bolin; ALt, 2001; Arduino et al., 2009).

Este trabalho teve como objetivo avaliar a utilização de uma vacina experimental, elaborada após determinação sorológica das sorovariedades mais prevalentes em bovinos de leite de uma propriedade tipo empresarial, assim como acompanhar a resposta imune pela determinação dos níveis de anticorpos antileptospiras e seus reflexos sobre o controle da infecção.

\section{MATERIAL E MÉTODOS}

Este estudo foi realizado em uma fazenda da bacia leiteira do município de Parnaíba, localizada no município de Buriti dos Lopes, regiáo norte do estado do Piauí. O município está situado a $300 \mathrm{~km}$ de Teresina e apresenta como coordenadas geográficas $3^{\circ} 5^{\prime} \mathrm{S}$ e $40^{\circ} 41^{\prime} \mathrm{W}$. O clima da região, segundo classificação climática de Koppen é Aw, tem estação seca bem definida (julho a dezembro). Na última década, a região apresentou médias anuais de umidade relativa de $74,9 \%$, precipitação de $965 \mathrm{~mm}$, concentrada no período de janeiro a junho (estação chuvosa,), temperatura média máxima do ar de $36^{\circ} \mathrm{C}$, e mínima de $22^{\circ} \mathrm{C}$ (Medeiros, 2004).

A fazenda possuía 255 vacas (62,20\% de vacas jovens), número de crias de 1 a 10 e peso ao primeiro parto de $480 \mathrm{~kg}$. $\mathrm{O}$ sistema de criaçấo era o de semiconfinamento, com duas ordenhas mecânicas por dia. Os currais eram lavados antes de cada ordenha, com mangueira de jato forte.

Em julho de 2004, observou-se em 85 vacas $(33,3 \%)$ a ocorrência em forma de surto, até então não registrado, do aumento do número de abortamentos no terço final da gestaçáo; da morte de 30 bezerros com icterícia, com menos de 14 dias de idade, e 18 vacas com hematúria. O médico veterinário suspeitou de leptospirose. $\mathrm{O}$ rebanho apresentava resultados negativos, em testes recentes de brucelose, para diarreia bovina a vírus, rinotraqueíte infecciosa e tuberculose. Para confirmaçáo do diagnóstico clínico de leptospirose, procedeu-se à colheita de amostras de soro sanguíneo das 255 vacas e dos 2 touros.

As vacas foram submetidas a 12 colheitas de sangue para obtenção de soro e realização de testes sorológicos em intervalos de seis meses. Para a pesquisa de aglutininas antileptospiras, utilizou-se a prova de soroaglutinação microscópica (SAM), segundo as recomendaçóes de Galton et al. (1965) e Cole JR. et al. (1973), contra 11 sorovares patogênicos: Bratislava, Ballum, Canicola, Gripothyphosa, Icterohaemorragiae, Szwajizak, Mini, Pomona, Hardjoprajitno (OMS), Hardjoprajitno (Norma), Hardjo (hardjobovis). As leituras foram realizadas em microscópio de campo escuro, objetiva 10x. O critério adotado para o soro ser considerado como reagente foi de $50 \%$ de leptospiras aglutinadas por campo microscópico em aumento de 100 vezes. O sorovar registrado foi aquele que apresentou maior título, sendo as demais aglutinaçóes consideradas reaçóes cruzadas. As amostras positivas ao título inicial foram novamente diluídas sucessivamente, na razão dois, e testadas para o(s) sorovar(es) que reagiram anteriormente. $\mathrm{O}$ título final foi aquele que ainda apresentou $50 \%$ ou mais de aglutinaçáo, sendo o ponto de corte da reação o título de 1:100.

A colheita de soro foi realizada a cada 180 dias por um período de 72 meses, em um total de 12 colheitas. Por ocasião da sexta colheita, 30 amostras de urina foram obtidas de forma asséptica, de animais positivos à sorologia (sorovar Hardjo) e com histórico de 
problemas reprodutivos. As amostras foram submetidas à microscopia de campo escuro e, em seguida, foram inoculadas em meio de cultura (EMJH modificado) para posterior isolamento.

Uma vacina experimental foi testada para o controle da leptospirose, produzida pelo Laboratório de Leptospirose da Escola de Veterinária da Universidade Federal de Minas Gerais (EV/UFMG), em Belo Horizonte, contendo os sorovares Hardjoprajitno, com os sorogrupos Norma e OMS e Hardjobovis cultivados em meio EMJH modificado, fração "V" de albumina bovina (Ellinghausen; Mccullough, 1965), por um período de 14 dias a $28^{\circ} \mathrm{C}$. Foi feita a contagem aproximada de $2 \times 10^{8}$ bactérias $/ \mathrm{mL}$, inativada com formalina na concentração final de $0,3 \%$, dividida em três alíquotas de $1000 \mu \mathrm{L}$, emulsionada no adjuvante Emulsigen ${ }^{\circledR}$ a $20 \%$ e adsorvida em um homogeneizador circular por 24 horas, $96 \mathrm{~g}$ e padronizada em $1 \times 10^{8}$ células por $\mathrm{mL}$ (Escala Mcfarland). A dose utilizada em cada vaca foi de 5,0 mL, inoculada por via subcutânea na região do terço proximal do pescoço. A vacina foi avaliada previamente com relaçáo à pureza, inocuidade e esterilidade, conforme procedimento recomendado (USDA, 1976).

A primeira vacinação do rebanho foi realizada apenas com os sorovares Hardjoprajitno Norma e OMS. Com o resultado da sorologia das seis primeiras colheitas, constatou-se a presença do sorovar Hardjobovis infectando o rebanho, o que levou à inclusão desse sorovar na formulação da vacina.

As 255 vacas foram vacinadas após o diagnóstico da infecção e revacinadas aos 45 dias e, a seguir, semestralmente. A utilização da vacinação associada à instituiçấo de quimioterapia, à base de estreptomicina, na dosagem de $50 \mathrm{mg} / \mathrm{kg}$ de peso vivo, foram as medidas adotadas, mas também foram introduzidas outras medidas de manejo, como separação e isolamento dos animais com manifestaçôes clínicas de hematúria; abortamentos; repetições de cio; intensificação da limpeza das instalaçôes, especialmente dos depósitos de armazenamento de raçóes, para evitar a presença de roedores; separaçấo do rebanho do convívio com outros animais domésticos, como cáes; e precauçôes com as práticas de manejo dos animais pelos empregados da fazenda para evitar uma possível contaminação. Os animais com comprovação clínica e sorológica de infecção não foram comercializados, e novos animais náo foram introduzidos no rebanho. $\mathrm{O}$ acompanhamento do rebanho vacinado foi realizado por meio da colheita de sangue para realizaçáo da técnica de SAM.

A organização da base de dados e a confecção de tabelas e gráficos foram realizadas em planilhas eletrônicas do programa Microsoft Excel, versão 2007. Na base de dados, cada amostra de soro sanguíneo era acompanhada pelos seguintes dados: data de colheita, sorovar utilizado na bateria de antígenos, resultado das reaçóes à SAM e títulos. As diferenças observadas nos índices quando da primeira leitura foram realizadas pelo teste do qui-quadrado, com nível de significância de 5\%.

Para avaliar a eficiência da vacina, considerando a inexistência de grupo controle e admitindo-se 50\% de redução da prevalência devido ao acaso, aplicou-se a prova de confronto de taxas Odds Ratio (OR) para a = 0,05 (BioEstat $^{\circledR}$, versão 3.0).

Este trabalho foi realizado conforme os princípios éticos da experimentação animal estabelecidos pelo Comitê de Ética em Experimentação com Animais, da Universidade do Piauí, conforme consta na declaraçáo emitida em 11 de outubro de 2011 pela coordenadora do Comitê.

\section{RESULTADOS}

Na primeira colheita de material para a realização do teste de SAM, em 7 de julho de 2004, as frequências de aglutininas antileptospira apresentaram taxas elevadas de positividade para os sorovares diagnosticados: Hardjobovis (54,50\%), Hardjo Norma (45,50\%) e Hardjo OMS (56,50\%).

Foi observada diferença estatística entre os sorovares com reação positiva, que consistiam de 3 sorovares diferentes e os outros 8 sorovares testados, perfazendo um total de 11 sorovares testados. No entanto, não houve diferença $(\mathrm{p}>0,05)$ entre os sorovares Hardjobovis $(54,50 \%)$ x Norma $(45,50 \%)$ e Hardjobovis $(54,50 \%)$ $\mathrm{x}$ OMS $(56,50)$.

As 11 colheitas subsequentes foram semestrais e realizadas no período de 2004 a 2009. Elas revelaram queda gradativa na positividade (Tabela 1; Fig. 1). A partir do segundo ano da vacinação, já foi possível observar redução na ocorrência dos problemas reprodutivos existentes previamente, como abortamentos, em 30\% (76/255); mamites, em 35\% (90/255); mortes de bezerros, em 25\% (64/255); e repetiçâo de estro, em 30\% (76/255). A incidência desses distúrbios foi reduzindo ano após ano, até não mais serem observados, a partir do quarto ano após a vacinação. Neste contexto, cabe destacar que houve queda expressiva de abortamento comparando o ano de 2004, quando ocorreu o surto da doença na propriedade, com o ano de 2009, quando a doença já estava controlada. Em todas as colheitas, até o desaparecimento de reagentes, houve predomínio de Hardjobovis sobre as demais sorovariedades. A tentativa de cultivo de leptospiras em 30 amostras de urina náo revelou crescimento da bactéria. Na Tabela 2 e na Fig. 1, observa-se que a Odds Ratio $(\mathrm{OR})$ indica queda real da prevalência atribuível à vacina, gradativa e crescente. 
Tabela 1. Reagentes para sorovares de Leptospira spp. em vacas leiteiras, município de Buriti dos Lopes, Piauí, Brasil, soroaglutinação microscópica, doze colheitas, 2004 - 2009.

\begin{tabular}{lccccccccc} 
& \multicolumn{3}{c}{ Hardjobovis } & \multicolumn{4}{c}{ Hardjoprajitno (Norma) } & \multicolumn{3}{c}{ Hardjoprajitno (OMS) } \\
\cline { 2 - 11 } 1 & Positivo & Negativo & $\%$ & Positivo & Negativo & $\%$ & Positivo & Negativo & $\%$ \\
\hline 2 & 139 & 116 & 54,5 & 116 & 139 & 45,5 & 144 & 111 & 56,5 \\
\hline 3 & 125 & 130 & 49 & 89 & 166 & 35 & 102 & 153 & 40 \\
\hline 4 & 101 & 154 & 39,6 & 72 & 123 & 28,2 & 89 & 166 & 35 \\
\hline 5 & 99 & 156 & 38,8 & 67 & 188 & 26 & 85 & 170 & 33,4 \\
\hline 6 & 109 & 146 & 42,7 & 65 & 190 & 25,5 & 89 & 171 & 32,9 \\
\hline 7 & 102 & 152 & 40,1 & 62 & 192 & 24,4 & 76 & 178 & 30 \\
\hline 8 & 83 & 169 & 33 & 54 & 198 & 21,4 & 52 & 20 & 20,6 \\
\hline 9 & 50 & 200 & 20 & 26 & 224 & 10,4 & 19 & 231 & 7,8 \\
\hline 10 & 21 & 226 & 8,4 & 13 & 234 & 5,2 & 12 & 235 & 4,8 \\
\hline 11 & 17 & 230 & 6,8 & 7 & 240 & 2,8 & 6 & 241 & 2,4 \\
\hline 12 & 4 & 243 & 1,6 & 0 & 24 & 0 & 0 & 247 & 0 \\
\hline
\end{tabular}

Hardjobovis $\left(\mathrm{OR}_{1}=2,44\right.$ e IC95\% 2,09 - 2,79; OR $=1,79$ e IC95\% 1,441-2,139; OR $=40,77$ e IC95\% 39,76-41,78) p < 0,0001; NORMA $\left(\mathrm{OR}_{1}=2,58\right.$ e IC95\% 2,204-2,956; OR = 11,07 e IC95\% 10,27-11,87) p < 0,0001; OMS (OR $=3,00$ e IC95\% 2,703-3,297; $\mathrm{OR}_{2}=17,14$ e IC95\% 16,29-17,99) $\mathrm{p}<0,0001$.

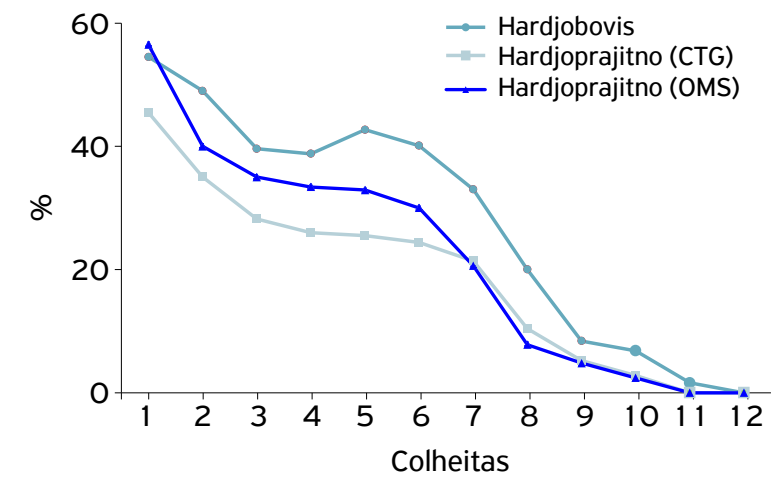

Figura 1. Positividade para diferentes sorovariedades de leptospiras em bovinos de leite, Buriti dos Lopes, Piauí, segundo colheitas semestrais, pós vacinação, 2004 - 2009.

\section{DISCUSSÃO}

Os sorovares de leptospiras descritos infectando bovinos no Brasil são: Pomona, Icterohaemorrhagiae, Grippothyphosa, Bratislava, Canicola, Ballum, Szwajisak e Hardjo (Zacarias et al., 2008; Mineiro et al., 2010; Silva et al., 2012). No surto de abortamento no rebanho leiteiro deste estudo, observou-se a ocorrência do sorovar Hardjo, com as sorovariantes Hardjobovis, Norma e OMS, e uma resposta positiva frente à vacina experimental utilizada. $\mathrm{O}$ papel de Hardjo como a principal sorovariedade patogênica para bovinos é registrado universalmente (GroOMs, 2006; MineIro et al., 2007; RyAn et al., 2012). É fato conhecido que o sorovar Hardjo produz infecção crônica em bovinos e reduz a produção animal, por comprometimento das funçóes reprodutivas (FAINE et al., 1999), como foi observado no rebanho objeto do presente estudo. Apesar da cepa Hardjobovis nunca ter sido isolada no Brasil, a existência
Tabela 2. Reagentes para sorovares de Leptospira spp. em vacas leiteiras, município de Buriti dos Lopes, Piauí, Brasil, soroaglutinação microscópica, primeira colheita, 2004.

\begin{tabular}{lrcc} 
& \multicolumn{3}{c}{ Amostras } \\
\cline { 2 - 4 } Sorovariedades & Positivas & Negativas & $\begin{array}{c}\% \text { de } \\
\text { Positivas }\end{array}$ \\
Hardjobov & 139 & 116 & 54,50 \\
\hline Hardjoprajitno (Norma) & 116 & 139 & 45,50 \\
\hline Hardjoprajitno (OMS) & 144 & 111 & 56,50 \\
\hline Mini & 0 & 255 & 0,00 \\
\hline Grippotyphosa & 0 & 255 & 0,00 \\
\hline Pomona & 0 & 255 & 0,00 \\
\hline Icterohaemorrhagiae & 0 & 255 & 0,00 \\
\hline Canicola & 0 & 255 & 0,00 \\
\hline Bratislava & 0 & 255 & 0,00 \\
\hline Canicola & 0 & 255 & 0,00 \\
\hline Ballum & 0 & 255 & 0,00 \\
\hline
\end{tabular}

*Hardjobovis $x$ demais sorovares $\chi^{2}=261,83$; NORMA $x$ demais sorovares $\chi^{2}=123,53$; OMS $x$ demais sorovares $\chi^{2}=290,37$; Hardjobovis $x$ NORMA $\chi^{2}=9,83$; Hardjobovis $\times$ OMS $\chi^{2}=1,03$.

de animais reagentes pelo teste de soroaglutinação microscópica é identificada quando Hardjobovis faz parte da coleção de antígenos utilizados no diagnóstico sorológico, como observado neste estudo. $\mathrm{Na}$ coleção de antígenos utilizada para o diagnóstico sorológico (coleção de antígenos do Laboratório de Leptospirose da Escola de Veterinária da Universidade Federal de Minas Gerais), a cepa Hardjobovis é mantida em cultivo como parte da coleçáo, tendo sido obtida junto ao National Collaborating Center for Reference and Research on Leptospirosis, em Amsterdã, na Holanda.

Embora no decorrer do experimento tenha havido redução progressiva na frequência de aglutininas antileptospira no rebanho, não podemos associar esses resultados com a melhora na performance reprodutiva dos animais. Contudo, em trabalho realizado 
em vacas de corte com vacina monovalente de Leptospira borgpetersenii serovar Hardjo cepa Hardjobovis, associada à administração parenteral de oxitetraciclina, nenhuma melhora significante da performance reprodutiva foi observada (KaSIMANICKAM et al., 2007).

O percentual de $54,5 \%$ de positivos na primeira colheita, associado à apresentação de histórico de abortamento e mastites, confirmou a existência da infecção no rebanho. Resultados com percentuais inferiores foram encontrados em rebanhos do estado do Maranháo (35,94\%) (Silva et al., 2012), enquanto no norte do estado do Piauí foi encontrado 52,86\% de positividade, sendo 38,10\% para Hardjo (Mineiro et al., 2007); mas percentuais superiores (97\%) foram registrados no estado da Paraíba (Thompson et al., 2006). Estes resultados mostram a gravidade e a distribuição da leptospirose no Brasil. Como doença que afeta os órgãos reprodutivos, é fácil perceber o potencial do rebanho bovino nacional se a leptospirose for controlada por medidas adequadas de controle, incluindo a vacinaçáo, associadas à melhoria do manejo sanitário e à instituiçấo de tratamento nos animais doentes. Tais medidas podem reduzir a taxa de infecçáo, como observado no presente estudo, protegendo contra a doença e evitando a excreçáo de leptospiras pela urina (AdLer; Moctezuma, 2010). Observou-se que o uso de vacina contendo sorovares presentes no rebanho, associado a melhores práticas de manejo sanitário, levou a uma queda progressiva até o desaparecimento completo de animais reagentes, o que foi constatado também em estudo semelhante (Chiareli et al., 2012). Desse modo, verifica-se a importância da identificação de variantes sorológicas de leptospiras em um rebanho, para que seja adotado o uso de vacinas polivalentes adequadas, tendo em vista que a imunidade é específica para cada sorovar, muito embora o antígeno de leptospira apresente baixa imunogenicidade, induzindo respostas imunológicas às vezes ineficientes (FAINE et al., 1999). Isto decorre, provavelmente, da deficiente ativação de linfócitos $\mathrm{B}$ pelos lipopolissacarídeos da superfície bacteriana (Bulach et al., 2006). É interessante assinalar, também, que a mastite clínica associada à infecção por leptospiras pode ser minimizada pela vacinação (GREEN et al., 2007).

Neste contexto, sugerimos que esquemas adequados de vacinação sejam adotados para cada região e para cada rebanho, a depender dos sorovares diagnosticados. Mas cabe alertar que apesar de a vacinação reduzir a taxa de infecção, como observado no presente estudo, experimento realizado com a utilizaçáo de vacina monovalente contendo Leptospira interrogans sorovar Hardjobovis mostrou que tanto animais controles quanto vacinados, desafiados por instilação conjuntival de $1 \times 10^{5}$ células de Hardjo bovis por três dias consecutivos, tornaram-se infectados e eliminaram o sorovar Hardjo bovis na urina (BoLIn et al., 1991).

As variaçôes na incidência da infecção nas diferentes regiôes sugerem provável influência de alguns fatores, como densidade bovina, índice pluviométrico, tipo de solo, sistema de criação, proximidade de outras espécies animais, e acesso às aguadas por bovinos de propriedades diferentes (EluIs, 1994; FaINE et al., 1999; Томісн et al., 2007).
Os percentuais de positividade para cada sorovariedade detectados no rebanho sugerem que a infecção leptospírica se manteve, por meio da transmissão bovino/bovino, como sugerido também em outro estudo (Figueiredo et al., 2009). No caso específico de Hardjo, considera-se que a transmissão direta de bovino para bovino seja o mecanismo mais importante para sua manutenção no plantel (ELLIS, 1984).

Quanto à Hardjobovis observou-se entre a primeira e a sétima colheitas, quando a positividade tinha caído pela metade e ainda sem a aplicação do antígeno Hardjobovis (vacina), que aquela queda não ocorreu ao acaso $\left(\mathrm{OR}_{1}=2,44 ; \mathrm{IC} 95 \% 2,09-2,79 ; \mathrm{p}=0,99\right)$, o que parece indicar alguma interferência favorável dos inóculos Norma e OMS sobre a infecção, visto que os mesmos tinham sido inoculados quando da segunda visita (dois anos antes).

No primeiro mês pós-vacinação (entre a $\sigma^{\mathrm{a}} \mathrm{e}$ a $7^{\mathrm{a}}$ leituras) por Hardjobovis houve acréscimo na proteção, mas embora OR tenha sido significante $\left(\mathrm{OR}_{2}=1,79\right.$; IC95\% 1,441 - 2,139; $\mathrm{p}=0,99)$, é provável que parte dessa proteção seja residual à aplicação dos inóculos Norma + OMS; no entanto, a elevação de $38,8 \%$ para $42,7 \%$ entre a $4^{a}$ e a $5^{a}$ leituras permite supor que a proteção cruzada, se ocorreu, já não estava presente. Já quanto ao efeito propriamente dito de Hardjobovis, o confronto entre o momento da aplicação ( $\sigma^{a}$ leitura) e a última leitura com pelo menos um positivo (11 a leitura) foi altamente significante $\left(\mathrm{OR}_{3}=40,77 ;\right.$ IC95\% 39,76-41,78; $\left.\mathrm{p}=0,99\right)$.

Quanto à Norma, constatou-se que entre a primeira colheita e o momento em que a positividade caiu pela metade ( $6^{\mathrm{a}}$ leitura, portanto, dois anos), a redução não se deveu ao acaso $\left(\mathrm{OR}_{1}=2,58\right.$; IC 95\% 2,204-2,956; $\mathrm{p}=0,99$ ) e entre esta e a última leitura com pelo menos um positivo (10 leitura), o resultado foi altamente significante $\left(\mathrm{OR}_{2}=11,07 ; \mathrm{IC} 95 \% 10,27-11,87 ; \mathrm{p}=0,99\right)$. O aumento das significâncias no período faz supor que a proteção realmente manteve-se ao longo do tempo.

Quanto à OMS, a redução de positividade entre a primeira leitura (antes da vacinaçáo) e a sexta, quando a mesma caiu pela metade, não se deveu ao acaso $\left(\mathrm{OR}_{1}=3,0 ; \mathrm{IC} 95 \%\right.$ 2,703 - 3,297; $\mathrm{p}=0,99)$, e entre esta e a última, em que havia pelo menos um positivo (décima), a queda foi ainda maior $\left(\mathrm{OR}_{2}=17,14\right.$; IC95\% 16,29 - 17,99; $\mathrm{p}=0,99)$, o que sugere alto poder imunogênico do inóculo.

\section{CONCLUSÕES}

Os resultados mostraram que em bovinos leiteiros da bacia de Parnaiba (PI) ocorre leptospirose, sorovares Hardjobovis, Hardjoprajitno (Norma) e Hardjoprajitno (OMS), com predominância de Hardjobovis. A utilização de uma vacina contendo as sorovariedades mais prevalentes no rebanho, associada à intensificaçáo de práticas de manejo sanitário, aplicada semestralmente, ao longo de cinco anos, foi importante para a reduçáo dos títulos de anticorpos até o seu desaparecimento completo. 


\section{REFERÊNCIAS}

ADLER, B.; MOCTEZUMA, A.P. Leptospira and leptospirosis. Veterinary Microbiology, v.140, p.287-296, 2010.

ARAUJO, V.E.M.; MOREIRA, E.C.; NEVADA, L.A.B.; SILVA, J.A.; CONTRERAS, R.L. Frequência de aglutininas anti-Leptospira interrogans em soros sanguíneos de bovinos, em Minas Gerais, de 1980 a 2002. Arquivo Brasileiro de Medicina Veterinária e Zootecnia, v.57, p.430-435, 2005.

ARDUINO, G.G.C.; GIRIO, R.J.S.; MAGAJEVSKI, F.S.; PEREIRA, G.T. Títulos de anticorpos aglutinantes induzidos por vacinas comerciais contra leptospirose bovina. Pesquisa Veterinária Brasileira, v.29, p.575-582, 2009.

BOLIN, C.A.; PHIL, J.A.C.; ZUERNER, R.L.; TRUEBA, G. Effect of vaccination with a monovalent Leptospira interrogans serovar hardjo type Hardjo-bovis vaccine on type Hardjo-bovis infection of cattle. American Journal of Veterinary Research, v.52, p.16391643, 1991.

BOLIN, C.A.; ALT, D.P. Use of a monovalent leptospiral vaccine to prevent renal colonization and urinary shedding in cattle exposed to Leptospira borgpetersenii serovar Hardjo. American Journal of Veterinary Research, v.62, p.995-1000, 2001.

BULACH, D.M.; ZUERNER, R.L.; WILSON, P.; SEEMANN, T.; MCGRATH, A.; CULLEN, P.A.; DAVIS, J.; JOHNSON, M.; KUCZEK, E.; ALT, D.P.; PETERSON-BURCH, B.; COPPEL, R.L.; ROOD, J.I.; DAVIES, J.K.; ADLER, B. Genome reduction in Leptospira borgpetersenii reflects limited transmission potential. Proceedings of the National Academy of Sciences of the United States of America, v.103, p.14560-14565, 2006.

CASTRO, V.; AZEVEDO, S.S.; GOTTI, T.B.; BATISTA, C.S.A.; GENTILI, J.; MORAES, Z.M.; SOUZA, G.O.; VASCONCELOS, S.A.; GENOVEZ, M.E. Soroprevalência da leptospirose em fêmeas bovinas em idade reprodutiva no estado de São Paulo Brasil. Arquivos do Instituto Biológico de São Paulo, v.75, p.3-1 1, 2008.

COLE JUNIOR, J.R.; SULZER, C.R.; PURSELL, A.R. Improved microtechnique for the leptospiral microscopic agglutination test. Applied Microbiology, v.25 p.970-980, 1973.

CHIARELI, D.; COSATE, M.R.V.; MOREIRA, E.C.; LEITE, R.C.; LOBATO, F.C.F.; SILVA, J.A.; TEIXEIRA, J.F.B.; MARCELINO, A. P. Controle da leptospirose em bovinos de leite com vacina autógena em Santo Antônio do Monte, Minas Gerais. Pesquisa Veterinária Brasileira, v.32, p.633-639, 2012.

ELLINGHAUSEN, H.C.; MCCULLOUGH, W.G. Nutrition of Leptospira pomona and growth of 13 other serotypes: fractionation of oleic albumin complex and a medium of bovine albumin and polysorbate 80. American Journal of Veterinary Research, v.26, p.45-51, 1965.

ELLIS, W.A. Bovine leptospirosis in the tropics: prevalence, pathogenesis and control. Preventive Veterinary Medicine, v.2, p.411-421, 1984.
ELLIS, W.A. Leptospirosis as a cause of reproductive failure. Veterinary Clinics of North America: Food Animal Practice, v.10, p.463-78, 1994.

FIGUEIREDO, A.O.; PELLEGRIN, A.O.; GONÇALVES, V.S.P.; FREITAS, E.M.; MONTEIRO, L.A.R.C.; OLIVEIRA, J.M.; OSÓRIO, A.L.A.R. Prevalência e fatores de risco para a leptospirose em bovinos de Mato Grosso do Sul. Pesquisa Veterinária Brasileira, v.29, p.375-381, 2009.

GALTON, M.M.; SULZER, C.R.; SANTA ROSA, C.A.; FIELDS, M.J. Application of a microtechnique to the Agglutination Test for Leptospiral Antibodies. Applied Microbiology, v.13, p.81-85.1965.

GIVENS M.D.; MARLEY, M.S.D. Infectious causes of embryonic and fetal mortality. Theriogenology, v.70, p.270-285, 2008.

GREEN, M.J.; BRADLEY, A.J.; MEDLEY, G.F.; BROWNE, W.J. Cow, farm, and management factors during the dry period that determine the rate of clinical mastitis after calving. Journal of Dairy Science, v.90, p.3764-3776, 2007.

GROOMS, D.L. Reproductive losses caused by bovine viral diarrhea virus and leptospirosis. Theriogenology, v.66, p.624-628, 2006.

KASIMANICKAM, R.; WHITTIER, W.D.; COLLINS, J.C.; CURRIN, J.F.; INMAN, B.; HALL, J.B.; PELZER, K.D. A field study of the effects of a monovalent Leptospira borgpetersenii serovar Hardjo strain hardjobovis vaccine administered with oxytetracycline on reproductive performance in beefcattle. Journal of the American Veterinary Medical Association, v.231, p.1709-1714, 2007.

MARTINS, G.; PENNA, B.; LILENBAUM, W. Differences between seroreactivity to leptospirosis in dairy and beef cattle from the same herd in Rio de Janeiro, Brazil. Tropical Animal Health and Production, v.44, p.377-378, 2012.

MEDEIROS, R.M. Estudo Agrometeorológico para o Estado do Piauí. Piauí: Secretaria do Meio Ambiente e Recursos Hídricos do Estado do Piauí. 2004. $113 p$.

MINEIRO, A.L.B.B.; BEZERRA, E.E.A.; VASCONCELOS, S.A.; COSTA, F.A.L.; MACEDO, N.A. Infecção por leptospira em bovinos e sua associação com transtornos reprodutivos e condições climáticas. Arquivo Brasileiro de Medicina Veterinária e Zootecnia, v.59, p. $1103-1109,2007$.

MINEIRO, A.L.B.B.; VIEIRA, R.J.; FEITOSA, L.C.S.; BEZERRA, E.E.A.; COSTA, F.A.L. Pesquisa de sorovares de leptospiras em rebanho bovino leiteiro no estado do piauí, Brasil. Arquivos do Instituto Biológico, v.77, p.129-132, 2010.

MOREY, R.E.; GALLOWAY, R.L.; BRAGG, S.L.; STEIGERWALT, A.G.; MAYER, L.W.; LEVETT, P.N. Species-specific identification of Leptospiraceae by $16 \mathrm{~S}$ rRNA gene sequencing. Journal of Clinical Microbiology, v.44, p.3510-3516, 2006. 
OLIVEIRA, F.C.S.; AZEVEDO, S.S.; PINHEIRO, S.R.; BATISTA, C.S.A.; MORAES, Z.M.; SOUZA, G.O.; GONÇALVES, A.P.; VASCONCELLOS, S.A. Fatores de risco para a leptospirose em fêmeas bovinas em idade reprodutiva no Estado da Bahia, Nordeste do Brasil. Pesquisa Veterinária Brasileira, v.30, p.398-402, 2010.

PEROLAT, P.; MERIEN, F.; ELLIS, W.A.; BARATON, G. Characterization of Leptospira isolates from serovar hardjo by ribotyping, arbitrarily primed PCR, and mapped restriction site polymorphisms. Journal of Clinical Microbiology, v.32, p.1949-1957, 1994.

RAMADAS, P.; MARSHALL, R.B.; JARVIS, B.D. Species differentiation of Leptospira interrogans serovar hardjo strain Hardjobovis from strain Hardjoprajitno by DNA slot blot hybridization. Research in Veterinary Science, v.49, p.194-197, 1990.

RODRIGUES, R.O.; HERRMANN, G.P.; HEINEMANN, M.B.; LAGE, A.P.; LOPES, L.B.; MOREIRA, E.C. Comparação entre a imunidade induzida em bovinos vacinados com bacterinas polivalentes comerciais e uma monovalente experimental. Pesquisa Veterinária Brasileira, v.31, p.10-16, 2011.

RYAN, E.G.; LEONARD, N.; O'GRADY, L.; MORE, S.J.; DOHERTY, M.L. Seroprevalence of Leptospira Hardjo in the Irish suckler cattle population. Irish Veterinary Journal, v.65, 2012.

SILVA, F.J.; CONCEIÇÃO, W.L.F.; FAGLIARI, J.J.; GIRIO, R.J.S.; DIAS, R.A.; BORBA, M.R.; MATHIAS, L.A. Prevalência e fatores de risco de leptospirose bovina no Estado do Maranhão. Pesquisa Veterinária Brasileira, v.32, p.303-312, 2012.
THOMPSON, J.A.; LEITE, R.M.H.; GONÇALVES, V.S.P.; LEITE, R.C.; BANDEIRA, D.A.; HERRMANN, G.P.; MOREIRA, E.C.; PRADO, P.E.F.; LOBATO, Z.I.P.; BIRTO, C.P.T.; LAGE, A.P. Spatial hierarchical variances and age covariances for seroprevalence to Leptospira interrogans serovar hardjo, BoHV-1 and BVDV for cattle in the State of Paraíba, Brasil. Preventive Veterinary Medicine, v.76, p.290-301, 2006.

TOMICH, R.G.P.; BOMFIM, M.R.Q.; KOURY, M.C.; PELLEGRIN, A.O.; PELLEGRIN, L.A.; KO, A.I.; BARBOSA-STANCIOLI, E.F. Leptospirosis serosurvey in bovines from Brazilian Pantanal using IGG Elisa with recombinant protein LIPL32 and microscopic agglutination test. Brazilian Journal of Microbiology, v.38, p.674-680, 2007.

USDA. 1976. Internal reference guide for potency assay of Leptospira interrogans serotype grippotyphosa bacterins. USDA Veterinary Services, Ames, IA. 12p.

VASCONCELOS, S.A.; BARBARINI JR, O.; UMEHARA, O.; MORAIS, Z.M.; CORTEZ, A.; PINHEIRO, S.R.; FERREIRA, F.; FAVERO, A.C.M.; FERREIRA NETO, J.S. Leptospirose bovina. Níveis de ocorrência e sorotipos predominantes em rebanhos dos estados de Minas Gerais, São Paulo, Rio de Janeiro, Paraná, Rio Grande do Sul e Mato Grosso do Sul. Período de janeiro a abril de 1996. Arquivos do Instituto Biológico de São Paulo, v.64, p.7-15, 1997.

ZACARIAS, F.G.S.; VASCONCELLOS, S.A.; ANZAI, E.K.; GIRALDI, N.; FREITAS, J.C.; HARTSKEERL. Isolation of leptospira Serovars Canicola and Copenhageni from cattle urine in the state of Paraná, Brazil. Brazilian Journal of Microbiology, v.39, n.4, p.744-748, 2008. 